\title{
Back to the future: understanding and responding to alcohol use in Liverpool
}

\author{
Martin Whiteford* and Paula Byrne \\ University of Liverpool
}

\begin{abstract}
Popular narratives have variously depicted Liverpool as a city of decline, protest, revival and hedonism. From being the 'Detroit of England' to the 'alcohol capital of England', Liverpool is seen to spatially and discursively embody a 'place of chronicity'. In this paper, we explore the way in which place matters to health in order to critically interrogate why it is that Liverpool has consistently recorded the highest level of alcohol-related hospital admissions in England. To this end, we draw on qualitative interviews with health and social care practitioners working with people with complex alcohol needs. The interviews provide an important insight into the practical and policy realities of alcohol misuse in Liverpool. We further suggest that local responses to alcohol consumption and addiction are explicitly tied to both an imperative to overturn the city's negative reputation and self-image and a commitment to improving the health and well-being of high impact users.
\end{abstract}

Keywords: A\&E, alcohol, ethnography, homelessness, Liverpool.

\section{Introduction}

Every night, in town centres, hospitals and police stations across the country, people have to cope with the consequences of alcohol abuse, and the problem is getting worse. [T]his is one of the scandals of our society and I am determined to deal with it (Prime Minister David Cameron, 2012). ${ }^{1}$

As a matter of political, public and media concern alcohol is ubiquitous. The deleterious effects of hazardous and harmful drinking on individual drinkers, families, communities, workplaces and the NHS have elicited both comment and condemnation. ${ }^{2}$ it is estimated that excessive alcohol consumption costs the NHS $£ 2.7 \mathrm{bn}$ a year - of which accident and emergency (A\&E) services spent $£ 1$ bn in 2010/11 dealing with 200,000 alcohol-related hospital admissions - while the annual cost to the wider society has been put at $£ 17$ bn to $£ 22$ bn (Alcohol Concern, 2010; Campbell, 2011; Wintour and Ball, 2012). Linked to this, alcohol has been shown to be related to 70 per cent of $A \& E$ attendance at peak times (Alcohol Health Alliance, 2011). 
An established body of medical evidence clearly attests to the serious and devastating consequences of alcohol use on physical health and mental well-being. Alcohol contributes to over 40 health conditions and is a major or significant contributor to liver and heart diseases, cancers, depression and anxiety (DoH, 2007). The effects of alcohol misuse - excessive or inappropriate alcohol consumption - are not merely confined to ill-health but rather encompass a broad range of social problems including unemployment, homelessness, gambling, anti-social behaviour, family breakdown and teenage pregnancy (Fountain et al., 2003; DoH, 2008; Baggott, 2009). Even allowing for such demonstrable impacts on health, mortality, behaviour and the economy there is currently very little provision of treatment for alcohol dependency: 67 per cent of dependent or harmful drug users have access to treatment, compared with 5.7 per cent for alcohol. Modelling by Alcohol Concern (2011: 7) indicates that an extra investment of $£ 217 \mathrm{~m}$ invested in alcohol services - double the current level - would bring about an annual saving of $£ 1.7 \mathrm{bn}$ for the NHS in England.

As a political and policy meme David Cameron has vowed to tackle the 'scandal' of public drunkenness and alcohol abuse. Speaking at the Royal Victoria Infirmary in Newcastle-Upon-Tyne in February 2012, Cameron called time on cheap alcohol and its associated harms by appealing for such 'innovative' solutions as the introduction of 'drunk tanks', 'sobriety bracelets', 'booze buses' and 'zero tolerance' of drunken behaviour in A\&E departments. Putting flesh on these and other policy suggestions The Government's Alcohol Strategy claims to signify a radical crackdown on booze culture in the interests of public health and criminal justice (Home Office, 2012). As the Alcohol Strategy makes textually clear 'we have seen a culture grow where it has become acceptable to be excessively drunk in public and cause nuisance and harm to ourselves and others' (2012: 3). Seen through this critical lens populist (a levy to help fund the extra policing costs associated with late-night drunkenness) and punitive (the use of ankle tags and breath tests for minor offenders) policy measures work to influence and reinforce a sort of catalogue raisonné of neo-prohibition (Mellows, 2012).

Medical opinion and political anxiety as to the pervading harms of alcohol misuse have come to settle on the desideratum of enacting a uniform minimum price per unit for alcohol. Policymakers in the corridors of Westminster, Holyrood and Stormont, following the lead of the Alcohol Health Alliance (a coalition of 31 organisations) and an independent review of alcohol pricing and promotion conducted by the School of Health and Related Research (ScHARR) at Sheffield University, have signalled their support for minimum pricing and opposition to heavy discounting or loss-leading of alcohol by supermarkets and convenience stores (Carrell, 2012; Wintour, 2012; Winnett, 2012). ${ }^{3}$ In gesturing towards evidence-based solutions to reduce alcohol-related health harm this muscular incursion into the territory of the free market and jettisoning of "nudge theory' (Sustein and Thaler, 2008) would appear to signal an acceptance of the view 'that heavy drinking, even when not antisocial, can create measurable public harms' (Nicholls, 2012). On closer reading though we can also discern the clear imprint of a familiar trope: the 'reckless' behaviour of an 'irresponsible' minority. In making a direct and explicit appeal to 'responsibility and a sense of respect for others' the Conservative-Liberal Democrat Coalition government seems determined to remoralise drink and drunkenness following the imputed social licentiousness of the New Labour era. This avowed concern with tackling 'irresponsibility, ignorance and poor habits' can be seen as part of a wider political script to 'persuade and even compel 'problematic' populations to behave as the government would like' (Brown and Patrick, 2012). Here, then, the undeserving poor have mutated into the undeserving drinkers (see for example Mellows, 2012; Gold, 2012).

Contemporary representations and narratives of alcohol misuse are driven and shaped by axiomatic appeals to moral deficiency and cultural culpability. In this sense, 
social problems become indexically linked to social places. Thus, Sunderland has been inscribed with the status of 'Britain's drink death capital' while Liverpool carries the dubious sobriquet of 'alcohol abuse capital of England' (Gavaghan, 2012; Duffy, 2010; Williams, 2007a: 2011). Pressed into reductive and simplistic formulations this type of rhetoric and representation elides the material circumstances in which alcohol use and the burden of ill-health is situated. Reference to the deindustrialised heartlands of northern England and entrenched drinking cultures are casually evoked but rarely the subject of detailed examination or explanation. Practically this erasure serves to divorce alcohol consumption and addiction from a heuristic frame which is sensitive to the complex interplay between local practices and processes and wider structural dynamics by focusing narrowly and regressively on people's lifestyles 'choices'. As the Marmot Review (2010: 57) illustrates the relationship between socioeconomic status and alcohol is complex, although hospital admissions for alcohol specific conditions are associated with increased levels of deprivation. ${ }^{4}$ Seen in this way, the capitalising of Sunderland and Liverpool has far-reaching consequences both within and outwith these communities: it reinforces stereotypical representations of the decline of the once thriving industrial heartlands of northern England and has the potential to become a 'source of local municipal shame' (Beckingham, 2008: 311).

In August 2011, the North West Public Health Observatory released figures showing that Liverpool had the highest alcohol-related hospital admissions in England, measured against alcohol's contribution to acute and chronic conditions, for the second year in a row. The Local Alcohol Profiles for England contain 25 alcohol-related indicators for every Local Authority (LA) and 22 for every Primary Care Trust (PCT) in England (see Jones et al., 2008 for further elucidation). The indicators measure the impact of alcohol on local communities and include a national indicator generated by the Department Of Health - Admission episodes for alcohol-attributable conditions (previously National Indicator 39 or NI39). Annual rates for alcohol-related admissions in Liverpool were identified as standing at 3,114 (per 100,000 of the population). This represented 8 per cent of all episodes. In four of the nine preceding years, Liverpool was ranked $1^{\text {st }}$ for alcohol-related admissions for England. ${ }^{5}$

The use of cartographical representations and statistical rankings to give expression to the impact of alcohol is neither novel nor unique. Indeed, as the historian David Beckingham (2008) reminds us Liverpool's recent record has deep historical antecedents. Using archival analysis of nineteenth-century police records and newspaper accounts Beckingham reveals that Liverpool was credited with the unenviable title of the 'drink capital of England and Wales'. Beckingham's historical analysis offers two further important insights. The first is to query the very statistical basis upon which Liverpool was portrayed as the quintessential Victorian 'shock city'. The second relates to the way in which the local police and judiciary employed the use of maps and statistics in the production of a 'moral geography of drunkenness' (2008: 311).

Fast forward across space and time and it is clearly the case that the production and publication of the Local Alcohol Profiles for England has significantly enhanced our understanding of the geographical distribution of the negative consequences of drinking. Nonetheless its findings have been consistently cited by local and national media outlets to project an image of Liverpool as the 'alcohol capital of England' and 'capital of the binge culture' (Williams, 2007b: 2010). For Boland (2008: 356) the general tableau of media coverage in respect of Liverpool and Liverpudlians has worked to create or reinforce social (feckless, garrulous, militant) and spatial (decline, dereliction, decay) stereotypes and imagery. In this way the coupling of Liverpool and alcohol becomes both a social signifier and place characteristic. The vitality of this idea - Liverpool as a 'place of chronicity' - is not purely rhetorical but rather exerts a moral 
power that has wider practical implications and outcomes. As Galvani and Forrester have argued 'people with substance misuse problems are considered deviant, manipulating and undeserving or, at best, they are sick, out of control and in need of treatment. Rarely are they considered vulnerable people with complex histories of loss, abuse and trauma, who are in need of intensive care and support' (2011: 178).

Before introducing our empirical examination of alcohol-related hospital attendance in Liverpool, it is useful to draw attention to some more recent studies on the burden of alcohol consumption on accident and emergency departments in Liverpool. Luke et al (2002) have drawn the link between clubbing, emergency services and alcohol consumption. Over a twelve month period of investigation the authors identified 777 people who attended a nightclub in the city before going on to present at the A\&E department at the Royal Liverpool University Hospital. Of these 'nightclub cases' 249 were reported by medical and nursing staff as being clinically intoxicated. Luke et al go further and show that assault was the most significant precipitate of hospital care and facial lacerations were the most common injury (2002: 543). A similar story is to be found in a study carried out by Pirmohamed (2000) and his interlocutors who undertook a 2-month prospective survey in the Royal Liverpool University Hospital on the relationship between clinical assessment and alcohol-related attendance. To give a sense of scale alcohol-related problems were thought to be responsible for 12 per cent of all A\&E attendances and 6 per cent of all admissions (2000: 292). Pirmohamed et al make the crucial point that the financial and clinical burden of alcohol misuse extends beyond the parameters of $A \& E$ and continues with admission to hospital wards and out-patient attendances (2000: 294). From a more opaque angle, Stuart Jeffries' (2007) short article Excess All Areas is a largely impressionistic and loosely investigative attempt to make sense of why it is that Liverpool has the highest rate of alcohol-related hospital admissions in England. Jeffries promenades about the Liverpool streets, using the backdrop of the Everton-Liverpool derby, to both marvel and scorn at the city's assumed weakness for alcohol-fuelled hedonism and self-abuse. Resultantly, Jeffries not only reverts to stock characters and episodic observations but, and this is the crucial point, conflates description with explanation.

Remaining within this milieu the ensuing discussion asks: Why has Liverpool consistently recorded the highest level of alcohol-related hospital admissions in England? How does the city make sense of this discursive and spatial characterisation? And, relatedly, how has it practically (and effectively) responded to the burden of alcohol consumption and addiction placed on localised health and social care services?

The qualitative data presented in this paper is based on a research project which explored the support needs of 'frequent flyers' or high impact users. High impact users are a relatively small number of people with alcohol-related conditions who account for a relatively large number of presentations to $A \& E$ and admissions to hospital wards. This cohort of patients typically present with 'multiple morbidity' (defined as the coexistence of two or more long-term conditions in an individual) and an institutional background (prison, armed forces or experience of local authority care in childhood). High impact users, as evidenced in this empirical example, can be understood as multiply excluded homeless people (see Bowpitt et al., 2012: 3 for an exegesis). The lived reality of deep social exclusion and alcohol dependency in turn works to place a disproportionate burden on health, social and criminal justice services (Gilburt et al., 2012).

The study used an ethnographic design, combining participant observation and indepth interviews with 18 health and social care practitioners - including hospital clinicians; GPs; community nurses; social workers; substance misuse workers; homelessness agency staff and local government representatives. Ethnographic settings included health-clinics; day-centres; detox and rehabilitation facilities; hostels; 
hospital wards and on-the street. The collection of data took place between April 2011 and April 2012. Each interview was recorded and transcribed. Transcripts and ethnographic field-notes were coded using the framework provided by the interview schedules. We contend that the empirical contribution of this study resides in its careful ethnographic attention to the local context of 'health and place'. It further suggests that the symbolic representation of Liverpool as the de facto 'alcohol capital of England' provides invaluable insights into the framing of 'poor' places and people (Mooney and Hancock, 2010: 15).

\section{Liverpool's exceptionalism}

I cannot help feeling that the option of managed decline is one which we should not forget altogether. We must not expend all our limited resources in trying to make water flow uphill (Geoffrey Howe, 1981). ${ }^{6}$

From being the 'Florence of the North' to the 'Detroit of England' popular narratives have depicted Liverpool as a city apart (Belcham, 2006; Hatherley, 2010). In the midnineteenth century Liverpool was the handmaiden to Britain's colonial ambitions (Nassey Brown, 2004). In the late twentieth century the city was scarred by industrial decline and political turmoil (Frost and Phillips, 2011). In the first decade of the twentieth first century Liverpool was transformed by its successful bid to become the 2008 European Capital of Culture (Jones and Wilks-Heeg, 2004). Today Liverpool's exceptionalism is reflected and refracted through its self-image as a resurgent postindustrial city and its concomitant status as the most deprived city in England. Outwardly Liverpool continues to be associated with economic and demographic decline - spatially and discursively a 'place of chronicity'. The legacy of historical industrial decline is perhaps most clearly apparent in and through indices of material inequality and ill-health: Liverpool has the highest proportion of homes without people working in the UK (Gentleman, 2012); the third lowest life expectancy for both men and women in England and local residents are twice as likely to die from an alcohol-specific condition, such as liver disease, than the England average (Liverpool PCT, 2012).

Today Liverpool is a city of 466,000 people. ${ }^{7}$ Although routinely depicted as a prime example of a state-managed locality, Liverpool is a significant commercial and creative hub for the north west of England. As befits a cosmopolitan city Liverpool is home to internationally renowned museums, galleries and theatres while also being nationally recognised for its vibrant and eclectic night-time economy. Despite the city's recovery and reinvention it remains the most deprived local authority in England, characterised by 'substantial pockets of deprivation in terms of health, employment, income and living environment' (Liverpool City Council, 2011: 4).

\section{The impact of alcohol in Liverpool}

Liverpudlians enjoy a drink, from a cool cocktail to a hearty real ale. Their sense of fun and love of a great night out guarantee that the bars in Liverpool are lively and that Liverpool nightlife is legendary (Visit Liverpool, 2012). ${ }^{8}$

Liverpool presents an extraordinary site for excavating the relationship between alcohol consumption and the burden of ill-health. It is inarguably the case that alcohol occupies a central and organising role in the cultural and economic life of the city (see Waddington, 2012 for a succinct overview). Liverpool has, for instance, been voted the best city for Nightlife in the UK (Lloyd, 2012). Departing from these lines, Routledge 
(2010) takes the history of the Cains brewery as a metaphor for Liverpool's vertiginous rise, steady decline and slow re-emergence. The current context is perhaps most powerfully and persuasively captured in the abridged extract below:

[In Liverpool] there is a strong correlation between those areas experiencing the highest economic disadvantage in the city, and those most affected by alcoholrelated health harms. [In fact], even the more affluent wards in south Liverpool (e.g Mossley Hill, Church, Woolton) have alcohol-related admission rates equal to or slightly above the national average, while the most deprived wards in the city (e.g. Everton, Kirkdale, Princes Park) have admission rates over 3 times the national average (Liverpool PCT with Liverpool City Council, 2012:11)

The Liverpool evidence paints a compelling picture of the spiralling social and medical costs of alcohol use: the city has consistently ranked in the top 10 local authorities in England, for adults requiring hospital admissions due to alcohol, and among the top three local authorities, for admissions for children and young people (Liverpool PCT, 2012). In Liverpool over 42 per cent of the drinking population drink above the so-called lower risk and 1 in 7 drinkers drink at higher risk levels (Liverpool PCT, 2011: 5). Death rates from alcohol-related liver disease are currently 40 per cent higher in the North West than the rest of the country and Liverpool has the highest levels for men in the country and the second highest for women. It is also estimated that 37 per cent of violent crime and 70 per cent of sexual assaults in the city are alcohol-related (Williams, 2010). Further to this, research commissioned by North West Employers and Drink Wise North West (2012) has shown that the total financial and social cost of alcohol-related harm to Liverpool in $2010 / 11$ was $£ 228 m$, which in turn equated to $£ 513$ per person.

As outlined above, alcohol-related hospital admissions are associated with increased levels of deprivation. This common sense understanding was energetically embraced by a leading clinician:

[My] recollection of growing up in Liverpool in the seventies and eighties was that deindustrialisation seemed to chime with the intravenous drug epidemic. Now we are seeing patients with hepatitis $C$ after giving up intravenous drug use and moving on to alcohol as their drug of choice. We are seeing the aftershocks of evidence of the combination of alcohol and hepatitis C [leading] to accelerated liver disease.

\section{Before going on to add:}

These are not your sort of patients that are guzzling high class chardonnay. Actually the majority of them are patients who are drinking hazardously. It's people drinking cheap booze. I do think this is a new phenomenon and [it's related] to the price of booze and the availability of booze. If you go down to say Walton or Kirkdale or any of these areas that are highest on the list of alcoholrelated prevalence, not just liver disease but violence and all the curses that come with excess alcohol use, and you see the amount of Bargain Boozes that you just don't see in your leafy suburbs.

Care must be taken however in reifying this metonymic correlation. The argument that unfolds below suggests that while the deindustrialisation thesis provides a valuable carapace for understanding why it is that the city of Liverpool has consistently recorded the highest level of alcohol-related hospital admissions in England, it is only by turning our ethnographic gaze towards the dense thicket of local practices and 
processes that inform drinking behaviour and influence responses to alcohol-related harm can we begin to make sense of the impact of alcohol in Liverpool. In making this argument we implicate four additional factors that we believe go some way to explaining Liverpool's relationship with alcohol consumption and A\&E presentations: (1) a significant and stable homeless/hostel population; (2) the 'shift' from problematic opiate use to harmful alcohol consumption; (3) unplanned hospital discharge and (4) a paucity of preventative and reactive alcohol support services.

The relationship between homelessness and substance misuse has been widely documented (McNaughton, 2008; Ravenhill, 2008; Nettleton et al., 2012). In considering the interaction between housing needs and alcohol abuse a community nurse was moved to comment:

One of our biggest problems within Liverpool is alcohol. I would say probably 95 per cent of the patients l've seen will have an issue of drinking over 50 units of alcohol. I think one of the biggest gaps in alcohol services is meeting the needs of this client group.

A similar point was made by a GP:

We've got people dying all the time from liver disease and alcoholic-related conditions in our homeless population. We've got a massive problem with recurrent admissions.

The impact on A\&E was felt to be particularly acute:

Unfortunately because they are street drinkers they do drink a lot and they become unconscious or go to sleep even. Members of the public call ambulances. We had one guy this week come in three times on three separate occasions in the one day by ambulance, and wholly attributed to alcohol and that's a lot of work (A\&E nurse).

During the 1980s and 1990s Liverpool witnessed a significant rise in the number of injecting drug users (see for example Parker et al., 1997; Hickman, 2004; Ashton and Seymour, 2010). Ethnographic encounters in hostels and on-the streets of Liverpool suggest that for a significant minority opiate use had given way to alcohol dependency. Thus understood:

I've seen a lot of our drug users flip over to alcohol having never touched alcohol really. The problem with alcohol is that it has far greater repercussions [in terms] of people's health, it kills them quicker (community nurse).

Echoing this perspective:

Years ago the homeless were often the drug users but we don't see so much now. There is still the heroin and crack users but most of them have got alcohol problems and the problem we have now is with the Eastern Europeans that are coming in they are drinking hand gel and all sorts of strange stuff (A\&E nurse).

Reflecting further on this changing landscape:

We have stats that show that the situation has changed from being most homeless people having substance misuse problems...drug problems, mainly heroin, crack cocaine to alcohol. We have the stats there. We know that most 
p. 115. Back to the Future: Understanding and Responding to Alcohol Use in Liverpool

people in homeless services that have a substance misuse problem, that have a drug problem are in services, and we know that most people with an alcohol problem aren't in services. So that tells me that the alcohol services are not accessible or not suitable for our client group. (local government representative).

In 2006 Homeless Link (the national umbrella organisation for homeless service providers in England) in partnership with the Department of Health and the Department for Communities and Local Government developed the Hospital Admission and Discharge Protocol Guidelines. In response to this, Liverpool City Council and Liverpool PCT produced a joint protocol with the stated aim of preventing homelessness on discharge from hospital. ${ }^{9}$ Despite being held up as an important exemplar of good practice in the care and support of homeless people there was a growing awareness and sensitivity among some - albeit by no means all - frontline practitioners that the Liverpool protocol was poorly understood and unevenly implemented:

The hospital discharge policy is out of date. It needs reviewing; it's not working. When I have spoken to individual nurses they go 'oh, what hospital policy?' They're just not aware. We had one example where a patient was discharged back onto the streets and the nurse said: 'we'll just send you out an appointment.' How are you going to send it out? By carrier pigeon or something? (community nurse).

An alternative reading was offered by an A\&E nurse:

Our job in A\&E is to tackle the immediate and we have to pass them on to someone who can put their arms around them and complete the package. But I don't know whether the whole package is out there or whether it is but they just touch you on the shoulder rather than put their arms around you and take you away from the problem.

The above quote speaks of a tacit awareness of the lack of capacity - access to accommodation/social care thresholds - a theme that was taken up by a voluntary sector worker charged with bridging the artificial divide between healthcare and homelessness:

I would definitely say that after accommodation the most common issue is alcohol. I see it all the time. But the priority is always about getting people off the street. I will ring around the hostels and see if there are any beds available. That's the most time consuming and frustrating part of the job. The fact is there are never enough beds. But I also help people access benefits because if they don't have benefits then most hostels aren't going to take them on. And [access to and receipt of benefits] can be a real problem for the central and eastern European migrants. And often I will phone around the hostels and be told that the person you're phoning for has been excluded from the service because of their past behaviour.

The effect of this is that patients, particularly high impact users with a history of accessing healthcare in moments of corporal suffering and emotional extremis, ricochet around services or fall through the net in the absence of integrated assessment and support planning (Cornes and Manthorpe, 2011: 32).

Feeding directly into these debates was a clear recognition that alcohol treatment services were both inadequately funded and poorly structured to meet the demands of alcohol consumption and addiction across the city. Reflecting on the perceived 
Cinderella status of alcohol support and treatment services in Liverpool a social worker commented:

Oh there is a massive, massive gap around alcohol. It is just so big that everyone falls through it including professionals. We don't have anywhere for people to live that do not want to reduce their drinking. We just don't have it in Liverpool. Everybody wants to either make sure people are on a harm reduction pathway or you know they are looking to complete abstinence. But we have got to deal with a lot of complicated and challenging people that are just being moved from one service to the other. We just wait for that placement to break down...they contravene the rules by either bringing in alcohol or they turn up drunk or they attack a member of staff...alcohol services in general are so poor.

And similarly:

I think the problem really comes with the really complex cases; so people who are never going to stop drinking, who've got incontinence or care needs but aren't willing to address them or who are quite young. Usually you know if you've got care needs you're an older person but the social services really won't work with chaotic drinkers who are forty five and don't fit. I think that's where I would say the gap in provision really is; it's for drinkers with care needs and chronic health needs as well [voluntary sector manager].

While a more forceful interpretation was offered by an A\&E nurse:

I know that if these people get the right care as in detox, rehab, accommodation, we don't see them again. I know one person who has been rough sleeping for ten years and chaotic [using] alcohol and drugs, a regular attender here with loads of health problems loads of injuries. When he finally went to detox and went into rehab we didn't see him again. In fact the only time we see him is when he calls in to help other people, other service users' because he is now working in the field. I know that the list that was left this morning by the night staff every name on there is only coming in because they are homeless and the reason they are homeless is because they are an alcoholic; you know those two things go hand-inhand and they have lost accommodation due to their behaviour. But if they were given help to detox, go into rehab or had appropriate accommodation then they wouldn't be in A\&E.

Together, then, we have suggested that these four factors provide an explanatory framework for understanding alcohol-related A\&E attendances in Liverpool. In describing and tracing this complex geometry this account does not seek to abandon the importance of material poverty, clinical coding or specificity of local drinking cultures as causal factors (see also Liverpool Link, 2010). Empirically and conceptually, it has attempted to show that the relationship between alcohol consumption and accident and emergency attendance in Liverpool is better understood as a linked chain of individual actions, contextual constraints and institutional encounters.

\section{Exiting the "hall of shame'?}

We do not want Liverpool to have a reputation for harmful drinking, and we work hard with our partners to tackle alcohol misuse through awareness, intervention and treatment (Liverpool PCT, 2010). ${ }^{10}$ 
In response to these changing and challenging circumstances, Liverpool PCT with Liverpool City Council recently published its third Alcohol Strategy: Reducing Harm; Improving Care (2011-2014). Over the life of Alcohol Strategy, Liverpool will seek to increase capacity in alcohol treatment services to accommodate at least an additional 2,000 patients through community drop-in clinics; engage 11,000 people every year in alcohol Identification and Brief Advice (IBA); target over 120,000 increasing and high risk drinkers with alcohol resources and, arguably most strikingly of all, work towards reducing wholly attributable alcohol-related admissions by five per cent, based on their projected increase between April 2011 and April 2014. Viewed in a positive light, these commitments should be seen as an acknowledgement of the spiralling medical costs and social consequences of alcohol use in Liverpool. But, over and above this, these policies and interventions should also be seen as a reaction to the negative place imagery that has greeted the publication of the Local Alcohol Profiles for England and the accompanying media coverage.

By August 2012, the North West Public Health Observatory released figures showing Liverpool ranked $6^{\text {th }}$ out of 326 for 'admission episodes for alcohol-attributable conditions' in England (see www.lape.org.uk/natind.htl). On this occasion media coverage was surprisingly muted but quickly gave ground to Liverpool City Council's decision to establish a temporary 'wet facility' for street drinkers on a derelict plot of land on the edge of the city's regeneration showpiece, Liverpool One, a privately owned and privately patrolled shopping mall (Bartlett, 2012; Siddle, 2012). It remains to be seen whether the symbolic importance of the narrative that Liverpool is the de facto 'alcohol capital of England' will remain or wither amidst uncertainty over the future direction of the NHS on the one hand, and the scorched earth of austerity on the other (Jordon, 2012; Hancock et al., 2012). Liverpool, as with many other northern cities, is likely to be further disadvantaged by spending plans to replace an area's level of deprivation with the age of residents as the main basis for how the NHS's $£ 104.2 \mathrm{bn}$ budget in England is allocated (Campbell, 2012). Liverpool the poorest city in England and the hardest hit of the big cities in the UK by public spending cuts - a budget gap of $£ 141 \mathrm{~m}$ over the next two years - is quite likely to see a reversal in recent and fragile public health gains (see Ramesh, 2012 for a detailed exposition).

\section{Conclusion}

This paper has critically interrogated the construction and representation of Liverpool as the 'alcohol capital of England'. This popular understanding of Liverpool - as a 'place of chronicity' - is firmly of a piece with media images and political portrayals that have gained anchor and influence over the last three decades (see Boland, 2008: 6). In striving to explain the empirical reality of alcohol-related hospital admissions, we have argued for a more sensitive and critical engagement with the particularity of people and place. As part of this task we have documented some of the positive steps taken by the people of Liverpool to creatively and effectively transform the local therapeutic landscape in - and against - a context of economic crisis and welfare change. From a social and sociological perspective, we have argued that a fuller commitment to representing and explaining this concatenation offers an important platform from which to reinstate the efforts and endeavours of local communities struggling against the deadweight of externally imposed imaginings and the living legacy of health inequalities. 
p. 118. Back to the Future: Understanding and Responding to Alcohol Use in Liverpool

\section{Notes}

1 'PM highlights Impact of Alcohol on NHS' www.number10.gov.uk/news/alcohol-onnhs/

2 Hazardous drinking is considered to be drinking between 15 and 35 units for women and between 22 and 55 units a week for men. Harmful drinking levels are considered to be drinking more than 35 units a week for women and more than 50 units for men (Liverpool Community Health NHS Trust and Liverpool PCT, 2011).

3 In May 2012 the Scottish Government announced plans to introduce a minimum price for alcohol of 50p per unit. This compares to plans to consult on the introduction of $45 p$ floor price in England and Wales and a proposed charge of 45-50p in Northern Ireland.

${ }^{4}$ A recent guidance document issued by the NICE (2012:3/4) noted that people in the most deprived fifth of the country are: $2-3$ times more likely to die, in part, as a result of alcohol; 3-5 times more likely to die of an alcohol-specific cause and 2-5 times more likely to be admitted to hospital because of alcohol-use disorder.

5 Between 2002/03 and 2010/11 respectively, Liverpool's position out of 326 was $5^{\text {th }}$, $6^{\text {th }}, 5^{\text {th }}, 1^{\text {st }}, 1^{\text {st }}, 2^{\text {nd }}, 1^{\text {st }}$ and $1^{\text {st }}$.

6 The National Archives (2011) Cabinet Papers: 1915- 1981 www.nationalarchives.gov.uk/cabinetpapers/

7 Source: Office for National Statistics: Census 2011.

8 See www.visitliverpool.com

9 See www.homeless.org.uk/sites/default/files/Liverpool-Hospital-Admissons-andDischarge-Protocol-RLH.pdf

10 Comments attributed to unspecified spokesperson for Liverpool PCT in Duffy, T (2010) Liverpool Booze Culture highlighted by New Report, Liverpool Daily Post, 1 September 2010.

\section{Acknowledgements}

The research on which this paper draws is part of a larger study 'Exploring Knowledge and Use of Alcohol Services in Liverpool'. It was funded by Liverpool PCT (research award number, P017).

* Correspondence address: Dr. Martin Whiteford, Fellow of the Liverpool Health Inequalities Institute, Health Services Research, Block B, Waterhouse Buildings, 1-5 Brownlow Street, University of Liverpool, L69 3GL. Email: martin.whiteford@liverpool.ac.uk 
p. 119. Back to the Future: Understanding and Responding to Alcohol Use in Liverpool

\section{References}

Alcohol Concern (2011) Making Alcohol a Health Priority: Opportunities to Reduce Alcohol Harms and Rising Costs. London: Alcohol Concern.

Alcohol Health Alliance UK (2011) Healthy Lives, Healthy People: Our Strategy for Public Health - Consultation Response. London: Royal College of Physicians.

Ashton, R. and H. Seymour (2010) Public Health and the Origins of the Mersey Model of Harm Reduction. International Journal of Drug Policy, 21, 2, 94-96.

Baggott, R. (2009) Alcohol, Politics and Social Policy. Journal of Social Policy, 15, 4, 467-488.

Bartlett, D. (2012) Liverpool City Centre Alcohol Zone for Street Boozers Sparks Anger. Liverpool Echo, 28 August 2012.

Beckingham, D. (2008) Geographies of Drink Culture in Liverpool: Lessons from the Drink Capital of Nineteenth-Century England. Drugs: Education, Prevention, and Policy, 15, 3, 305-313.

Belcham, D. (2000) Merseyside: Essays in Liverpool Exceptionalism. Liverpool University Press, Liverpool.

Boland, P. (2008) The Construction of Images of People and Place: Labelling Liverpool and Stereotyping Scousers. Cities, 25, 6, 355-369.

Bowpitt, G., Dwyer, P., Sundin, E. \& Weinstein, M. (2011) The Home Study: Comparing the Priorities of Multiple Excluded Homeless People and Support Agencies. Swindon: ESCRC.

Brown, K. And Patrick, R. (2012) Re-moralising or De-moralising? The Coalition Government's Approach to 'Problematic' Populations: Editorial. People, Place and Policy Online, 6, 1, 41-53. http://extra.shu.ac.uk/ppponline/issue 1300312 /article 5 full.html

Campbell, D. (2011) Hospital Admissions due to Drink Double in 10 Years. The Guardian, 9 December 2011.

Carrell, S. (2012) Minimum Alcohol price in Scotland to be set at 50p a Unit. The Guardian, 14 May 2012.

Cornes, M. and Manthorpe, J. (2011) Tackling Homelessness and Multiple Exclusion. Community Care, 32-33, 24 November 2011.

Department of Health (2007) Safe. Sensible. Social: The Next Steps in the National Alcohol Strategy. London: DH Publications.

Department of Health (2008) Reducing Alcohol Harm: Health Services in England for Alcohol Misuse. Norwich: TSO (The Stationery Office).

Duffy, T. (2010) Liverpool Booze Culture Highlighted by New Report. Liverpool Daily Post, 1 September 2010.

Fountain, J., Howe, S., Marsden, J., Taylor, C. and Strang, J. (2003) Drug and Alcohol Use and the Link with Homelessness: Results from a Survey of Homeless People in London. Addiction Research and Theory, 11, 4, 245-256.

Frost, D. and Phillips, R. (2011) Liverpool 81: Remembering the Riots. Liverpool: Liverpool University Press.

Galvani, S. and Forrester, D. (2011) Guest Editorial: Alcohol and other Drugs in Social Work Practice. Practice: Social Work in Action, 23, 4, 177-182.

Gavaghan, J. (2012) Britain's Drink Death Capital: How More People Die from Alcohol in Sunderland than anywhere Else. Daily Mail Online, 14 March 2012.

Gentleman, A. (2012) Below the Breadline on Liverpool's Workless Estates. The Guardian, 16 January 2012.

Gilburt, H., Burns, T., Copello, A., Coulton, S., Crawford, M., Day, E., Deluca, P., Godfrey, C., Parrott, S., Rose, A.K., Sinclair, J.M., Wright, C. and Drummond, C. (2012) Assertive Community Treatment for Alcohol Dependence (ACTAD): Study Protocol for a Randomised Controlled Trial. Trials, 13, 9, 1-8. 
Gold, T. (2012) Minimum Alcohol Pricing? Blame those Vomiting Girls. The Guardian, 15 May 2012.

Hancock, L., Mooney, G. and Neal, S. (2012) Crisis Social Policy and the Resilience of the Concept of Community. Critical Social Policy, 32, 3, 343-364.

Hatherley, O. (2010) A Guide to the New Ruins of Great Britain. London: Verso.

HM Government (2012) The Government's Alcohol Strategy: Presented to Parliament for by the Secretary of State for the Home Department by Command of Her Majesty. London: Cm 8336.

Jeffries, S. (2007) Excess all Areas. The Guardian, 23 October 2007.

Jones, L., Bellis, M., Dedman, D., Sumnall, H. and Tocque, K. (2008) AlcoholAttributable Fractions for England; Alcohol-attributable Mortality and Hospital Admissions. Liverpool: Liverpool John Moores University.

Jones, P. and Wilks-Heeg, S. (2004) Capitalising Culture: Liverpool 2008. Local Economy, 19, 4, 341-360.

Jordon, H. (2012) Stemming the Tide. Drinking and Drug News, November 2012, 8-9.

Liverpool City Council (2011) The index of Multiple Deprivation 2010: A Liverpool Analysis. Liverpool: Liverpool City Council.

Liverpool Link (2010) Too Cheap, Too Strong, Too Available: Report of Liverpool Alcohol Task and Finish Group. Liverpool: LCVS.

Liverpool Community Health NHS Trust with Liverpool Primary Care Trust (2011) The Alcohol Handbook: A Professional's Guide to Tackling Alcohol-Related Harm in Liverpool. Liverpool: Liverpool PCT.

Liverpool Primary Care Trust and Liverpool City Council (2011) Reducing Harm, Improving Care: Liverpool Alcohol Strategy 2011-2014. Liverpool: Liverpool PCT.

Liverpool Primary Care Trust with Liverpool City Council (2012) Annual Report of the Joint Director of Public Health. Liverpool: Liverpool PCT.

Lloyd, D. (2012) Late Night Liverpool: The Party's Over? Sevenstreets - Making the Most of Liverpool http://www.sevenstreets.com/bars-and-nightlife/the-partysover-night/

Luke, L.C., Dewar, C., Bailey, M. McGreevy, D. Morris, H. and Burdett-Smith, P. (2002) A Little Nightclub Medicine: The Healthcare Implications of Clubbing. Emergency Medicine Journal, 19, 6, 542-545.

McNaughton, C. (2008) Transitions through Homelessness: Lives on the Edge. Basingstoke: Palgrave Macmillan.

Marmot Review (2010) Fair Society, Healthy Lives: The Marmot Review Strategic Review of Health Inequalities in England 2010. London: The Marmot Review.

Mellows, P. (2012) The Politics of Drinking. Phil Mellows: The Politics of Drinking...and More, 13 April 2012 www.philmellows.com/philmellows_diary_13_04_12.html

Mooney, G. and Hancock, L. (2010) Poverty Porn and the Broken Society. Variant, 39/40 www.variant.org.uk/39 40texts/povertp39 40.html

Nassy Brown, J. (2004) Dropping Anchor, Setting Sail: Geographies of Race in Black Liverpool. Princeton: Princeton University Press.

National Institute for Health and Clinical Excellence (2012) Local Public Health Briefings: Alcohol. http://publications.nice.org.uk/phb6

Nettleton, S., Neale, J. and Stevenson, C. (2012) Sleeping at the Margins: A Qualitative Study of Homeless Drug Users who stay in Emergency Hostels and Shelters. Critical Public Health, 22, 3, 319-328.

Nicholls, J. (2012) The New Alcohol Strategy Raises Some Old Questions. Huffington Post, 25 March 2012 www.huffingtonpost.co.uk/james-nicholls/the-alcoholstrategy-ques b 1378365.html

North West Employers and Drink Wise North West (2012) The Cost of Alcohol to the North West Economy Part A/Part B. Manchester: North West Employers.

North West Public Health Observatory (2011) Local Alcohol Profiles for England. Liverpool: Centre for Public Health: Liverpool John Moores University. 
Pirmohamed, M., Brown, C., Owens, L., Luke, C., Gilmore, I.T., Breckenridge, A.M. and Park, B.K. (2000) The Burden of Alcohol Misuse on an inner-city General Hospital. QJM, 93, 5, 291-295.

Ramesh, R. (2012) Caring for England's Poorest Patients: Liverpool GP who welcomes all-Comers. The Guardian, 22 May 2012.

Ravenhill, M. (2008) The Culture of Homelessness. Farnham: Ashgate.

Routledge, C. (2008) Cains: The Story of Liverpool in a Pint. Liverpool: Liverpool University Press.

Siddle, J. (2012) Liverpool Council to Press Ahead with Renshaw Street 'Drinking Zone' Despite Trade Anger. Liverpool Echo, 29 August 2012.

Sunstein, C. and Thaler, R. (2008) Nudge: Improving Decisions about Health, Wealth, and Happiness. New Haven: Yale University Press.

Waddington, M. (2012) Call for Liverpool Council to Prove Whether Rowdy Stag and Hen Nights Give City a ‘Bad Name’. Liverpool Echo, 1 October 2012.

Williams, L. (2007a) Liverpool - Capital of the Binge Culture. Liverpool Daily Post, 16 October 2007.

Williams, L. (2007b) Liverpool worst in England for Binge Drinking. Liverpool Daily Post, 16 October 2007.

Williams, L. (2010) Does Liverpool want Cheap Booze Ban? Liverpool Echo, 1 February 2010.

Williams, L. (2011) Liverpool Named Alcohol Abuse Capital for England for Second Year in a Row. Liverpool Echo, 31 August 2011.

Winnett, R. (2012) David Cameron to Launch Attack on Britain's 'Boozing Scandal'. The Telegraph, 14 February 2012.

Wintour, P. (2012) David Cameron Edges towards Minimum Price Curb on Binge Drinking. The Guardian, 15 February 2012.

Wintour, P. and Ball, J. (2012) Coalition to Set Minimum Alcohol Price. The Guardian, 23 March 2012. 